\title{
Imagined social structures: Mirrors or alternatives? A comparison between networks of characters in contemporary Dutch literature and networks of the population in the Netherlands
}

\author{
Beate Volker ${ }^{\mathrm{a}, *}$, Roel Smeets ${ }^{\mathrm{b}}$ \\ ${ }^{a}$ University of Amsterdam, Department of Sociology, The Netherlands \\ ${ }^{\mathrm{b}}$ University of Nijmegen, Department of Cultural Studies, The Netherlands
}

\section{A R T I C L E I N F O}

\section{Keywords:}

Literary social network analysis Homogeneity in literary social relationships Ego-networks in literature

\begin{abstract}
A B S T R A C T
We study whether patterns of segregation and homogeneity in personal networks in the Netherlands are comparable to the network structures of characters in modern Dutch literature and examine the degree to which social divides in terms of sex, education, ethnicity, and age are reflected in literary novels. A representative sample of people living in the Netherlands (the Survey of the Social Networks of the Dutch, SSND 2014, $\mathrm{n}=967$ respondents and 3424 network members) is employed as well as a representative sample from Dutch literary fiction published in 2012 and submitted to the Libris Prize ( $n=170$ books and 1292 characters). While controlling for author characteristics, our multilevel regression models reveal that networks in books are more diverse in terms of ethnicity, education and age. However, higher levels of education show more closure in books than in the actual world, and the same holds for characters with a higher age. We conclude with a discussion of the relationship between literature and society.
\end{abstract}

\section{Introduction}

In Dutch society, like in other modern western societies, severe social divides constitute challenges for the future. These are the divides according to differences in educational levels, ethnic background, age, and sex. People with different backgrounds in these regards are out of each other's sight and they have only little contact with each other. As a result, their networks do not overlap, and the social worlds of different groups are largely separated. In social science, divides are studied as patterns of social segregation and homogeneity in networks and it is argued that strong patterns of segregation hamper intergroup solidarity and diminish social cohesion (e.g. Briggs, 2001; Markovsky \& Lawler, 1994; Pettigrew, 1998). Importantly, if social divides recur in cultural domains, such as in fiction writing, social cohesion is probably even more threatened than actually thought, because the actually existing divides are not even bridged in the imagined social structures. Hence, the degree of network segregation in fiction writing can be perceived as an additional indicator of the strength of segregation and divides in the actual world.

This paper examines this issue and studies the question whether network patterns with regard to homogeneity and segregation of characters in books reflect network patterns of people in the Netherlands. Much research shows that people's networks are considerable homogenously composed in terms of important social background characteristics such as age, race, education, and sex. How is this in contemporary fiction writing? Is it likely that two befriended characters in a novel differ in ethnic background and/or education? And how likely is it that friends in a novel diverge in age? We employ two sets of data, a national representative dataset on

\footnotetext{
* Corresponding author.

E-mail address: b.volker@uva.nl (B. Volker).
} 
social networks of people living in the Netherlands (the Survey of the Networks of the Dutch, SSND, 2014) and a dataset of fictional networks constructed from books nominated for the Dutch LIBRIS prize in 2013, one of the most prestigious literary prizes in the Dutch language area. To our best knowledge, up until now a comparison between social networks in the real and the fictional world has not been carried out. The current research aims to provide a first exploration into this yet unknown interdisciplinary field.

In what follows we first briefly sketch our theoretical arguments and summarize important findings about personal networks patterns in the real world. Our section on measurements shows how we delineated the data and compared the two types of networks. Finally, we provide a multivariate logistic multilevel analysis and an analysis matching author's book networks with real-world networks discuss our findings.

\section{Background and arguments}

In what follows we briefly sketch the arguments from literary studies as well as from social science that are the basis of our inquiry.

\subsection{The relation between social structures and literary fiction}

In the first accounts of literary theory, in Aristoteles' Poetica (Aristoteles 2013 [335BC]), a core concept of literary theory is described: literature as a mimesis (imitation) of social reality. Framed as such, social structures are echoed in arts and literature. Ever since then, ideas and arguments regarding the relationship between literature and society have been shifting. In his famous book The Mirror and the Lamp (1953), Abrams claimed that pre-modern, classical literature imitates reality in the sense that it provides a realistic account of what is going on in a society, whereas in the eighteenth and nineteenth century Romanticist movement, modern literature becomes more of a vision of how society ought to be. ${ }^{1}$ From their special position, authors write texts about fictional worlds that do not necessarily conform with the social reality but depict imagined or desired worlds instead. ${ }^{2}$ Following this reasoning, societies portrayed in literary texts can contain social structures that might be unimagined or even unimageable in reality. ${ }^{3}$ Yet, the old metaphor of literature as a 'mirror' for society seems still to make sense (see, e.g., Sontag, 1966): There is a widely accepted idea that literature is a medium that reflects society (e.g. Hoggart, 1966; Anjana \& Bhambhra, 2016; Auerbach, 2003 [1946]). Issues that are at stake in society find their way into a literary novel. Throughout history, however, also the opposite can be observed: literature has had considerable impacts on society and the behavior of individuals. There are, for instance, numerous examples of firmly socially engaged books that influenced certain emancipatory movements. ${ }^{4}$ In addition, it should be mentioned that one of the most dominant forms of modern and contemporary literature can be labeled as realistic, or psychological-realistic. ${ }^{5}$ Realistic novels are close to 'the real world' in the sense that they resemble actual societies and are set in a world that could be ours.

In line with these arguments, we - very broadly - define two main strands of thinking about the relation between literature and society: first, the literary text portrays worlds with alternative social structures, that might be unrelated to the actual world, and second, the literary text is a mirror of society and social patterns in literature largely reflect patterns in society. With regard to the fictional populations depicted in literary novels, this raises the question to what extent the characters and their social networks actually resemble people and their social networks in society. More in specific, are literary worlds and networks as segregated as actual ones and can we understand differences in this regard?

\subsection{How does social segregation come about?}

Already in texts by ancient Greek philosophers, the preference for similar others has been identified as a strong organization principle of social worlds. For example, Plato noted in Phaedrus that "similarity begets friendship" (Plato, 1968:837[360BC]). Indeed, there is no other idea about principles behind social structures as well established as the principle of homophily with homogenously composed networks as a result. Homogeneity in networks seems to be remarkable robust in various types of relationships, from marriages and close friendships to even more distant acquaintances (see McPherson, Smith-Lovin, \& Cook, 2001, for an overview). Two types of arguments explain the emergence of such homogeneous social structures in general as well as social segregation in particular: demand side theories, which focus on individual preferences, and supply side theories, which are directed to the distribution of meeting chances in society. Important demand side perspectives based on alleged homogeneity preferences are balance theory (Curry \& Emerson, 1970; Heider, 1946; Newcomb, 1961 and later reformulations) and the theory of social capital (on

\footnotetext{
${ }^{1}$ Note, howeveer, that in the eighteenth century, there also emerged the widespread genre of 'literary realism', in which "the text's interplay with the "real world"' (Dickstein, 2007:1)

${ }^{2}$ Although the idea of literary autonomy emerged at the start of modernity, it is not the case that all pre-modern literature is necessarily tied to and reflective of social structures. There are numerous pre-modern literary texts that describe alternative social structures (e.g., Utopia (1516) by Thomas More).

${ }^{3}$ In an interview, Stanford scholar Claire Jarvis suggested something similar: To the question: 'Does literature represent sexuality in a way that Victorian society can't?', Jarvis answered: 'Literature can represent that divide more flexibly than something like the didactic essay or a news article could.' (https://fivebooks.com/best-books/sex-in-victorian-literature/).

${ }^{4}$ The most famous example is the anti-slavery novel Uncle Tom's Cabin; or, Life Among the Lowly (1852) by Stowe, which has been a major impulse for the anti-slavery movement.

${ }^{5}$ Some authors even speak of a 'return to realism' (e.g., Anjaria, 2017).
} 
the micro level, see Bourdieu, 1981; Flap \& Volker, 2004). Important supply side perspectives are (macro-) structuralism (Blau, 1977; Marsden, 1990), focus theory (Feld, 1981) and the choice constraint approach (Fischer et al., 1977; Fischer, 1982). Demand side theories state that people prefer to interact with those who are similar to them. Interactions with similar others are rewarding (Homans, 1984, 1950) and confirm each other's identity. As to the supply side perspectives, with Blau's (1977) structural approach as the most prominent theory, they focus on the contextual structures that determine the chances for interaction, regardless individual preferences for these contacts. Opportunities to associate with similar others depend on the numerical distribution of groups within the population or the accessible pool of particular individuals in a given social setting. Hence, patterns of homogeneity are strongly affected by the relative group size, the numerical chance of meeting each other, in the pool of all potential contacts. People with different backgrounds simply do not meet each other in their daily life. Schools, neighborhoods, clubs and work places are socially segregated, although the degree of segregation varies and differs for several dimensions of social divides. For example, work places are less segregated with respect to age than leisure time clubs; but these latter are often quite homogenous in terms of education and sex.

In the explanation of network homogeneity and social segregation, both perspectives seem to reinforce each other: meeting places are often homogeneously composed, and people select similar others into their networks because they prefer to be surrounded by people like themselves. Together, these two arguments explain why people end up with networks that are largely homogeneous. In a benchmark article, Marsden (1986) showed that networks of confiding ties in the US are small, close knit, and highly homogeneous with regard to important socio-demographic dimensions. As shown, a very important divide is the divide due to race. For example, only eight percent of adult respondents in a national sample mention that they have a close network-tie to a person with another race (Marsden op. cit., Britton, 2011; Rydgren, Sofi, \& Hällsten, 2013; Smith, 2017). Other important divides exist between differences in educational levels, age-groups, and sex. E.g., the chance of being a friend with somebody from the same sex is between six and twenty times higher than the chance of befriending a person of the opposite sex, depending on the source of the sample (Booth \& Hess, 1974; Fischer et al., 1977; Kalmijn, 2002; Verbrugge, 1977). With regard to age divides, Fischer et al. (1977) found that thirty-eight percent of the respondents' close friends were within two years of their age. Finally, concerning education, Marden (op. cit.) found about thirty percent of the networks were homogeneous in terms of education (see also Allan, 1977; Chan \& Goldthorpe, 2004). Interestingly, inbreeding tendencies seem to be highest in the edge categories of high and lower educated, respectively (Kalmijn, 1998).

In summary, it has been theoretically argued and empirically shown that personal networks are homogeneous with respect to important socio-demographic characteristic such as education, ethnicity, age, and sex. Network homogeneity reinforces all kinds of social divides and is a result of two entangled processes, i.e. the preference for similar others and the segregated meeting opportunities in the settings people enter in their daily life.

\subsection{Putting it together}

Our study aims bringing together the arguments from literary studies about the relationship between society and literature with the arguments from social sciences about the emergence of segregation structures. As to the network structures of homogeneity, we inquire into the similarity between network members in books and in society according to the four important social divides, education, ethnicity, age, and sex. We also compare these networks in terms of common patterns, such as composition and size as well as multiplexity of the relationships.

In addition, and obviously, authors are the intermediaries between 'literature' and 'society'. Authors might write what they observe but they also might depict other social worlds; worlds they imagine as a dystopian consequence of existing social structures, or, opposingly, worlds in which currently existing problems are solved and which could be an alternative society. Therefore, we pay specific attention to author characteristics in our empirical account and inquire how they are related to the networks of characters in their books.

\section{Data, measurements and analytical strategy}

Two data sets are employed, a sample of the population in the Netherlands (The Survey of the Social Networks of the Dutch, SSND, 2014) and a sample of Dutch literary fiction novels nominated for a literary prize, the so-called LIBRIS prize (2013).

\subsection{Data}

\subsubsection{The survey of the social networks of the Dutch - SSND}

The SSND is a longitudinal network study in the Netherlands that started in 1999 and has been ended in 2018. At four points in time, networks of people living in the Netherlands have been studied extensively (Volker \& Mollenhorst, 2014). The data used a number of measurements for delineating personal networks (see below) and social capital. The population sample was drawn from a sample of neighborhoods, delineated by 5 of the 6 digits in the postal codes of the Netherlands in a sample of Dutch municipalities. In the second wave (2007) and the third wave (2014) next to the panel also a new sample has been added. This way, the study allows for the analysis of longitudinal developments as well as cross-sectional comparisons. The last wave was finished in 2018 and focused only on people who had participated in the study before $(n=574)$. Wave $1-3$ contained respectively 1007 , 998 and 1069 respondents. For this study the sample of the third SSND wave is employed, since the time of data collection corresponds best with the publication of the novels. 


\subsubsection{The literary data - LIBRIS}

Our second employed dataset contains data with regard to fictional characters in contemporary Dutch literature; a sample of Dutch novels. The characters in those novels make up a 'fictional population' that we compared to the actual Dutch population. The 'fictional population' here represents all fictional characters that inhabit the literary narratives of a certain time and place. ${ }^{6}$ As such, there is a contemporary Dutch fictional population, just as there is a contemporary Dutch population.

For the present research, a sample of the contemporary Dutch fictional population has been taken from earlier research (Van der Deijl, Prinse, Pieterse, \& Smeets, 2016). It consists of the novels submitted to one of the most prestigious literary prizes in the Dutch language area, the 'Libris Literatuurprijs', in the year of $2013(\mathrm{n}=170)^{7}$ As this prize is granted to novels published in the year before, this means that all novels are published in 2012. Thus, the sample is taken from the Dutch fictional population from 2012. 1397 Dutch books in the category of literary fiction have been published in this year, hence our sample represents 12.2 percent of the total population of novels published in that year. ${ }^{8}$ The 170 books comprised 1292 different characters and their demographic characteristics as well as the network relations were semi-automatically coded (see Van der Deijl et al., 2016).

\subsection{Measurements}

\subsubsection{Network delineation}

The delineation of networks in the SSND followed established methods for the collection of network data. Through a number of relatively standard name generating questions (see below), people were asked for their network members and for activities they undertake with each other. This way a list of persons was made who all have a particular function in a person's network. In a second step the names of the network members were 'interpreted' by asking for a number of characteristics of these persons. This way, similarity between the respondent (ego) and the network members (alters) has been established.

Name generators in the SSND aim at delineating stronger as well as weaker network ties. One of the classic questions for the delineation of moderately strong ties is the so- called core discussion name generating question "With whom did you discuss important matters during the last six months?" (see Marsden, 1986). This question is assumed to tap into the stronger part of a personal network, but independent of role labels such as 'friendship'. In other words, it is deliberately not asked for friends to a avoid cultural biases in the implication of this role relation. Furthermore, it is an advantage that a person can mention also other roles than friends in this part of a personal network. Next to the core discussion question we used the alters mentioned in reaction to the question 'with whom do you work together?', 'who do you ask for help with odd jobs in and around the house', 'who is annoying you?' and 'who else is important but not on this list' as the sample of personal network members that were used in the analyses.

In the LIBRIS data, there is of course no other option than delineating the networks of characters featuring in the book as a personal network. In this contribution we consider networks in books as ego-centered networks, a perspective which is close to the network data from the SSND. The characters in a book are conceived as 'ego' and all his or her relationships mentioned are seen as the network that we examine (the 'alters' in the personal network). We studied all characters in a book as well as their network relationships. In the analyses the average network size of characters in books. Furthermore, in the descriptive analyses of the LIBRIS data, we also controlled for the number of characters in books as well as the number of relationships between the alters and the network density. Network density of characters is calculated as the ratio between actual connections and possible connections, while we assumed that all characters in books are possible network relationships. ${ }^{9}$

\subsubsection{Similarity of sex, age, education, and origin}

We directed our analyses on four dimensions of similarity between the relationships of the literary characters, or respectively, the respondents in our survey data (both referred to as 'ego') and their network members ('alters'). These four dimensions are education, age, sex, and country of origin. These characteristics are available from all respondents in the SSND and from all characters in the books, as well as from both their network members. Data have been harmonized, i.e. all codings have been made comparable. Note, that characteristics like education and age remained often implicit in the book, resulting in a relative high number of missing variables. For sex and origin, coding was very straightforward, and the percentage of missing variables is very low (not even one percent). For age and education however, almost 30\% of the values are missing, because it was not possible to add a coding given the information in the book. We did not apply any imputation for missing data but left them out of the analysis.

In both data, the four similarity variables were coded as follows:

Education: is a binary variable, ' 1 ' indicates finished higher education, i.e. at least college (Dutch: HBO) or university, '0 'indicates and educational level below that. Having college education or not is one of the major educational divides (see McPherson et al., 2001).

\footnotetext{
${ }^{6}$ 'Dutch literature' refers to a set of novels published in the Dutch language. 'Dutch novels', then, are not necessarily written by authors that were born or currently live in the Netherlands. In practice, this means that 'Dutch writers' refer to both Dutch and Flemish authors, as well as to other authors that write in Dutch but do not have the Dutch nationality

${ }^{7}$ For a list of all 170 novels see: http://www.librisliteratuurprijs.nl/2013-groslijst

${ }^{8}$ This number is based on all Dutch language novels published in 2012 with NUR-code 301 (literary fiction), which is a total of 1780. There are 383 duplicates or reissues among those novels, which are subtracted from the total amount. Thus, the total amount of 'original' Dutch literary fiction published in 2012 is 1397.

${ }^{9}$ The number of possible connections is calculated as $\frac{n \times(n-1)}{2}$, where $\mathrm{n}=$ the number of network members (see Wasserman and Faust, 1994).
} 
Sex: female is coded with ' 0 ', male with ' 1 '.

Age: is measured in 6 categories, 0-25 (1), 26-34 (2), 35-44 (3), 45-54 (4), 55-64 (5), 65 and more (6).

Country of origin is coded ' 0 ' if a person is born abroad and ' 1 ' if a person was born in the Netherlands.

\subsubsection{Role relationships}

In order to measure network composition, we coded the different role relationships which relate ego and alter. In the SSND these were categories of which respondents could choose from. In the LIBRIS data relations in the books have been coded in the order in which they appeared in the text. We distinguished between partner (1), parent (2), child (3), sibling (4), parent in law (5), other family (6), friendship (7), negative relation (8) and work relation (9). In the SSND, people also mentioned neighbors (10) in reaction to the name generating questions, but in the LIBRIS data this was not a meaningful category.

\subsubsection{Multiplexity}

Multiplexity indicates whether a relationship comprises multiple layers or functions, for example when a relation is a friend as well as a colleague. It is also perceived as another indicator of relational strength. We counted this type of role multiplexity in both data sets.

\subsubsection{Opportunity structures}

In order to put our findings on similarity in context we need to control for the opportunity structure in the books. For example, a finding on the similarity of a certain dyad does not tell much if all potential other dyads are also similar. Therefore, we controlled in the analyses for the number of, e.g. persons with a high education, a high age, given sex or ethnicity in the books (LIBRIS data). For the analyses of the SSND, we controlled for the number of persons with such characteristics in the network. For example, when estimating the likelihood that a specific dyad in a network is similar with regard to sex, we included the number of men in the network or in the book, respectively.

\subsection{Analytical strategy and modelling}

The dependent variables similarity of sex, age, education or origin, respectively, are established by binary variables indicating whether ego and alter have the same characteristic of not. For example, if both interaction partners are male, the variable sexsimilarity is coded 1 , if they have different sex it is coded 0 . This way, all dyads between the focal actor - the respondent or the main character in a book - and his/her network members have been coded.

Independent variables in our analyses are characteristics of ego such as age, education, sex and origin. Furthermore, we included the role relationships of partner/lover, friend, negative relationship, and colleague in the analyses, hence we controlled for achieved, as well as non-kin relationships as opposed to kin-ties. We also examined the degree to which similarity in a given dimension predicts similarity in another one. For example, it is plausible to expect that similarity in education is predicted by similarity in age.

Last but not least, we controlled for role multiplexity, because effects of role relationships might be affected by multiplexity. Other important control variables are the author characteristics, these are the same as for ego and network members, i.e. sex, age, education and ethnicity.

For the analysis we applied the following strategy. First, we considered the respondents and the fictional characters as a sample of a population and compared their characteristics with data from Statistics Netherlands. Next, networks of respondents and book characters are described in terms of composition and similarity of dyads. While estimating the parameters, it is taken into account that the network relationships are not independent from each other but depend on 'ego'. Technically, relationships are nested within persons. While ordinary regression models assume that observations are independent, multilevel techniques account for the nested structure of the data (see Snijders \& Bosker, 1999). By including books and respondents (ego) as a separate level in the model we take into account that the data about network members are not independent from each other. In previous analyses we distinguished three levels: books, characters in books, and relationships for the LIBRIS data.

We are aware that there is an important difference between networks in books and networks in the actual world in the way we measured them: in the books, the network members of a given person are also focal actors, or in other words, 'egos' are also 'alters'. We tackled this problem by running a number of additional analyses, while including only the first character and the books written in a first-person style. Results did not lead to other conclusions than we report here.

\section{Results}

From the 170 books, $28.9 \%$ were written by a woman. $25 \%$ of the authors is between 55 and 65 years of age, only $13 \%$ are between 35 and 45 years of age. More than two third have an education in Humanities and about 20\% are educated in the social sciences. $78 \%$ of the authors is born in the Netherlands.

On average, a book consists of 7-8 characters with a minimum of 2 and a maximum of 27 characters. The networks in each book comprise between 1 and 17 alters with an average of 3.9 (standard deviation 1.6). Furthermore, on average there are 26.4 relations in a book, although the distribution is skewed to the left, as figure 1 shows. Fig. 1 illustrates the distribution of the number of persons per book, the number of network members in networks as well as the number of relationships. The first part of the figure shows that it is rare that a book contains more than 10 characters. Furthermore, since we concentrated on the direct ties of the main character, network size is smaller than the number of characters in books: networks consist usually of not more than 4 persons. The largest 
Table 1

Author characteristics and average characteristics of networks in books.

\begin{tabular}{|c|c|c|c|c|}
\hline & $\mathrm{n}$ of characters in books & $\mathrm{n}$ of network members & $\mathrm{n}$ of relationships per book & Density of networks in books \\
\hline \multicolumn{5}{|l|}{ Author's sex: } \\
\hline Female & $9.52(3.52)$ & $5.38(2.82)$ & $23.8(17.6)$ & $0.57(.22)$ \\
\hline Male & $8.98(3.43)$ & $4.51(2.22)$ & $16.9(10.4)$ & $0.49(.18)$ \\
\hline \multicolumn{5}{|l|}{ Country of birth } \\
\hline Netherlands & $8.84(3.01)$ & $4.70(2.44)$ & $18.27(12.81)$ & $0.49(.21)$ \\
\hline Somewhere else & $10.38(4.32)$ & $5.23(2.49)$ & $23.4(15.05)$ & $0.52(.19)$ \\
\hline \multicolumn{5}{|l|}{ Age: } \\
\hline Below 25 & - & - & - & - \\
\hline $25-34$ & $7.11(1.87)$ & $4.24(2.06)$ & $13.22(7.61)$ & $0.58(.18)$ \\
\hline $35-44$ & 9.49 (4.97) & $4.59(2.21)$ & $18.44(13.74)$ & $0.49(.20)$ \\
\hline $45-54$ & $9.07(2.45)$ & $4.59(2.21)$ & $17.57(8.66)$ & $0.48(.16)$ \\
\hline $55-64$ & $9.53(3.29)$ & $5.19(2.70)$ & $22.37(15.90)$ & $0.53(.21)$ \\
\hline $65+$ & $9.15(3.54)$ & $5.01(2.77)$ & $20.72(16.30)$ & $0.54(.21)$ \\
\hline \multicolumn{5}{|l|}{ Type of education } \\
\hline Humanities & $9.65(2.87)$ & $4.87(2.52)$ & $20.7(14.8)$ & $0.50(.19)$ \\
\hline Social Science & $7.98(2.62)$ & $4.48(2.06)$ & $15.9(9.7)$ & $0.57(.17)$ \\
\hline Natural Science & $10.01(1.23)$ & $5.26(2.26)$ & $21.5(7.7)$ & $0.46(.09)$ \\
\hline Arts & $8.48(2.43)$ & $4.36(2.13)$ & $15.1(7.2)$ & $0.48(.18)$ \\
\hline Total & $9.10(3.5)$ & $4.80(2.5)$ & $19.40(13.5)$ & $0.52(.19)$ \\
\hline
\end{tabular}

Note: outliers are removed from the description, see text.

number of characters/persons in a book with by far the highest number of relationships is in the book Zeep (soap), written by Nico van Wijk. In the description in Table 1, this book was not included because it would bias the figures. In the multivariate analyses, all books and their characters have been included.

\subsection{Authors and networks in their books}

Is the network structure in books depending on the characteristics of the writers? And, if so, in what way or to what degree? Table 1 shows the association between author characteristics and average number of characters in books, average number of network member per character and the number of relations per book. The last column provides the density of the networks of characters in books. Regarding the characteristics of the writers, we inquired into the same dimensions of social divides as in the network analyses, i.e. sex, ethnic background, age, and education. Since by far most of the writers are highly educated, we report the type of their education, i.e. humanities, social sciences, natural sciences, or arts.

The table shows that there are interesting and important differences in networks in books associated with writers' demography: male authors write about less characters with smaller networks and, consequently less relationships per book. Also, the density of networks in their books is lower indicating that there are less ties between characters described by male authors.

It also matters whether a writer is born in the Netherlands or anywhere else. Writers with foreign roots depict a larger number of relationships in their books. Further, with increasing age authors sketch more characters with more relationships and with a higher network density. The latter is interesting since density is usually lower when there are more ties. Finally, the type of education plays a role for the network structures described. Characters in books and their networks depicted by authors who graduated in humanities are larger than those who graduated in arts and in the social sciences. Interestingly, authors who graduated in the natural sciences depict the highest number of characters in books. However, these latter figures are not valid, since there are only very few authors with a diploma in natural sciences. In a bivariate analysis, all the differences mentioned here are significant.

\subsection{Demography of people and characters in books}

Table 2 compares our data with data from the population in the Netherlands between 2012 and 2014. The population data come from Statistics Netherlands (2018). With regard to sex, the SSND is well comparable with the population, whereas in the LIBRIS data females are underrepresented. In addition, in both data the percentage of higher educated is much larger than in the population in the Netherlands. The percentage of people born outside of the Netherlands is in the SSND lower than in the population, but considerably higher in the LIBRIS. Lastly, the age distribution is skewed in both data, in the SSND there are more elderly than in the population while in the LIBRIS the younger strata (in particular those with an age between 25 and 35) are overrepresented.

Table 3 shows the composition of networks in the SSND and the LIBRIS. In the SSND the network delineation resulted in 932 respondents with 3424 relationships, while networks of respondents consist on average of 4,9 relationships with a maximum of 13 . Interestingly, the focus on partner or lover is much larger in the fictional literature than in the actual social networks. While parents are a bit more prominent, the general focus on family is rather similar. Furthermore, neighbors do not feature as important roles in the networks of books, but they do in the actual networks of people in the Netherlands. It seems that neighbors are no important relational category in contemporary Dutch literature. The p-value in the last column indicates the degree to which the difference in numbers can be attributed to chance; smaller $\mathrm{p}$ values indicate that the difference found is unlikely due to chance. 
Table 2

Basic demographic characteristics in the SSND, LIBRIS and in the population of the Netherlands.

\begin{tabular}{|c|c|c|c|c|c|}
\hline & \multicolumn{2}{|c|}{$\begin{array}{l}\text { SSND (2014, n = } 967 \text { egos and } 3424 \\
\text { alters) }\end{array}$} & \multicolumn{2}{|c|}{$\begin{array}{l}\text { LIBRIS (2012, } \mathrm{n}=170 \text { books with } 1297 \\
\text { characters) }\end{array}$} & \multirow[t]{2}{*}{$\begin{array}{l}\text { Population in the Netherlands } \\
(2012-2014)^{\mathrm{a}}\end{array}$} \\
\hline & ego & alters & ego & alters & \\
\hline$\%$ female & 52.6 & 41.3 & 31.3 & 48.8 & 50.1 \\
\hline$\%$ higher educated & 40.7 & 35.5 & 74.5 & 69.5 & 29.2 \\
\hline $\begin{array}{l}\% \text { not born in NL } \\
\text { Age distribution }\end{array}$ & 7.0 & 8.3 & 33.2 & 58.9 & 11.7 \\
\hline Below 25 years of age & 1.0 & 6.0 & 29.3 & 35.2 & 29.4 \\
\hline 25-35 & 4.5 & 11.6 & 22.2 & 19.1 & 12.1 \\
\hline $35-45$ & 11.3 & 21.3 & 14.8 & 13.4 & 13.7 \\
\hline $45-55$ & 22.7 & 24.3 & 14.6 & 8.7 & 15.0 \\
\hline $55-65$ & 29.0 & 19.7 & 6.3 & 6.6 & 12.9 \\
\hline 65 and more years of age & 31.6 & 17.1 & 12.9 & 17.9 & 16.8 \\
\hline
\end{tabular}

a Source: Statistics Netherlands.

Table 3

Differences in the network composition between the SSND and the LIBRIS.

\begin{tabular}{|c|c|c|c|}
\hline & SSND $(n=3424)$ & LIBRIS ( $\mathrm{n}=1297$ ) & $\mathrm{p}$ value \\
\hline Partner/lover & 8.6 & 22.0 & $.000^{3 k \cdots k}$ \\
\hline Parent & 4.1 & 7.7 & $.000^{\text {knk }}$ \\
\hline Child & 12.1 & 11.0 & .068 \\
\hline Parent in law & 1.1 & 4.1 & $.000^{\text {t.kek }}$ \\
\hline Sibling & 7.7 & 6.9 & $.017^{* * k}$ \\
\hline Other family & 8.7 & 7.1 & .128 \\
\hline Friend & 11.6 & 12.3 & .194 \\
\hline Negative relation & 11.7 & 5.2 & $.000^{3 * \ldots * k}$ \\
\hline Work relation & 21.1 & 28.2 & $.000^{* k * k}$ \\
\hline Neighbor & 20.3 & - & \\
\hline Multiplexity & $1-3$, average: $1.03(.488)$ & $1-4$, average: $1.170(.420)$ & \\
\hline Network size & $1-13$, average $4.97(2.33)$ & $1-16$, average $5.4(3.2)$ & \\
\hline
\end{tabular}

Numbers do not add up to $100 \%$ due to multiple role relationships, i.e. multiplexity.

$* * * \mathrm{p}<.001$

$* * \mathrm{p}<.05$.

Table 4

Dyad similarity per network, broken down by similarity categories SSND $\mathrm{n}=950$, Libris $\mathrm{n}=170$ ).

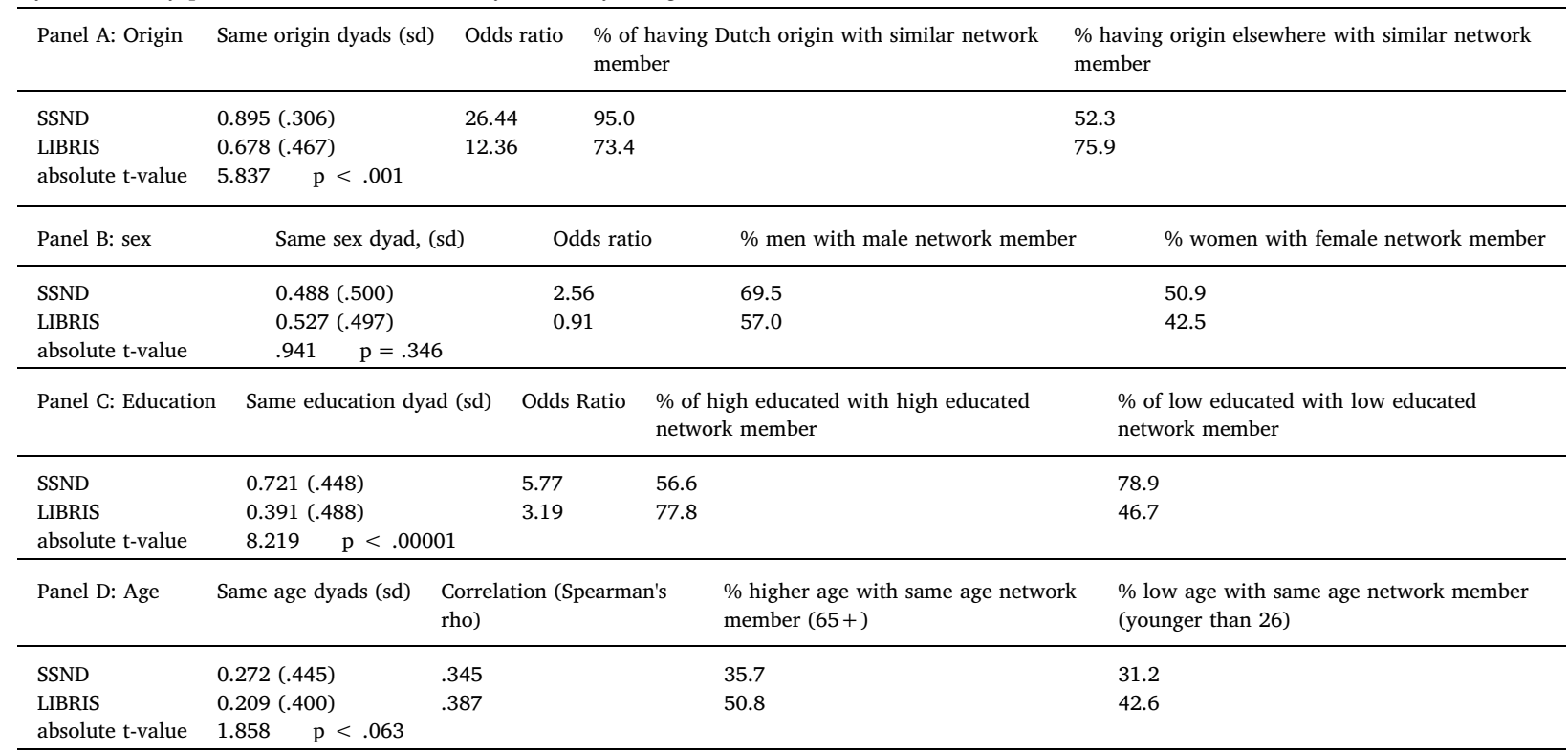


How similar are the dyads in the networks in the LIBRIS and the SSND data? Table 4 describes and compares the degree to which interaction partners share the same sociodemographic characteristics. Differences in three of the four dimensions are significant, as indicated by the p-values - the number of similar dyads in terms of sex does not differ between LIBRIS and SSND. ${ }^{10}$ In the SSND there are more similar dyads regarding origin, education, and age than in the LIBRIS data. With regard to origin the odds ratio shows that the likelihood that a person who is born in the Netherlands is associated with someone from the same origin is about 26 times higher than the likelihood for the association of a person born outside of the Netherlands with someone born in the Netherlands. For the LIBRIS data, the odds ratio is also substantially in its magnitude, but remarkably lower. For sex dyads there is no statistical difference found between the two types of data. However, sex segregation in the real world seems to differ from the world of books: while realworld networks are sex segregated, although not as much as for education and origin, networks in books seem to be reversed, as the odds for men to associate with a women are slightly higher than for the association with a man, indicated by the odds ratio lower than 1. Further, both types of networks are segregated in terms of education, the SSND networks in general more than the networks in books. For age dyads, differences are smaller and show only borderline significance, but still there are more age similar dyads in the SSND than in the networks in the books.

In order to inquire more into segregation patterns, Table 4 shows also the number of the similarity scores broken down by the different categories. With regard to origin, it shows that there is a remarkable divide in associations between people of a similar background in the SSND: while 95\% of those who are born in the Netherlands have a network member with similar roots, only about $52 \%$ of those born outside of the Netherlands have a relationship with someone also born outside. In the LIBRIS data both types of relationships are relatively evenly distributed: about $73 \%$ of those born in the Netherlands have similar ties in this regard and likewise about $76 \%$ of those born outside maintain a relation with a similar other. Further, in both data, men have more often contact with men than women with women. The pattern for education is also interesting: in the SSND about $56.6 \%$ of the high educated maintain a relationship with a high educated network member and about $78.9 \%$ of the low educated maintain a relationship with a low educated person. This pattern is reversed in the LIBRIS data: here, almost $78 \%$ of the high educated have a relation with a similar educated person against only $47 \%$ of the low educated with a low educated person. Interestingly, the percentage book characters with higher age, who have a similar network member is higher in the books than in the actual world: $50.8 \%$ compared to $35.7 \%$. In general, social networks become more age-diverse when people grow older (e.g. Mollenhorst, Volker, \& Flap, 2008), hence, authors seem to depict this not conform with the reality.

Fig. 2 below illustrates the average number of similar dyads and shows in addition how the four dimensions of similarity differ within the two data sets: similarity in terms of origin is highest, followed by education in the SSND data but by sex similarity in the books. Age similar dyads occur least frequent in both books as well as in the real-world networks.

\subsection{Explaining dyad similarity}

In the following the multilevel regression models that predict dyad similarity are summarized. In all models it is controlled for respondent or main character characteristics (ego), author characteristics (for the LIBRIS data), role relationships, similarity with network member (alter) and opportunity structure. Only the coefficients of variables that show effect in either the SSND or the LIBRIS data are presented. The models are presented in Tables $5 \mathrm{a}-5 \mathrm{~d}$.

First, similarity in origin, presented in Table 5a, is strongly predicted by the origin of ego in the SSND; which also holds in the LIBRIS data, but the coefficients are much smaller. Furthermore, education and age similarity are associated with similarity in origin in the SSND, in the LIBRIS this is found only for age similarity. In the LIBRIS the educational level of ego is found to predict similarity in origin: higher educated have a higher chance for an origin-similar dyad. In both data, negative relationships have a higher chance of being dissimilar in origin and, interestingly, in the LIBRIS data the same holds for partners or lovers. Finally, and interestingly, authors not born in the Netherlands write about more origin-similar dyads in their books.

Next, when predicting sex similarity (Table 5b), we found that sex of the actual respondent or literary character clearly predicts sex-similar dyads: men tend to have more sex similar relationships than women. This holds in both sets of data. Furthermore, and not in line with what one would expect, similarity of sex is negatively related with multiplexity. In addition, colleagues and friends are often similar with regard to sex, while, not surprising, partners usually have the opposite sex. Next to this, in the LIBRIS data, also friends and negative relationships have a high chance of being similar with regard to sex. Finally, in the LIBRIS data but not in the SSND, people who are similar in education have a higher chance to be also similar in their sex. The intraclass-correlation (ICC) in Table $5 \mathrm{~b}$ indicates that for the LIBRIS data about $22 \%$ of the variation in the data is due to the differences in the books. For the SSND data only $6 \%$ of this variation is due to differences among persons.

Predicting educational similarity (Table $5 \mathrm{c}$ ) shows the following pattern: conform with the descriptive analyses, the effect of education differs between the SSND and the LIBRIS data. In the SSND, higher educated persons have smaller chance to be associated with another highly educated person (Odds ratio 0.301) In the LIBRIS data this is reversed, and high education persons have a considerable higher chance of educational similarity (Odds ratio 6.9). Furthermore, in the SSND - the actual world - educational similarity is found for many types of relationships, i.e. negative relations, friends, partners, and colleagues. In the literature networks, only negative relationships and colleagues are related to education but the association is reversed: colleagues and negative relationships are rather different in their education than similar. Furthermore, in the LIBRIS data, educational similarity is predicted by similarity in sex and age, which is not found in the SSND. Last but not least, the more persons in a book the higher the chance of

\footnotetext{
${ }^{10}$ The difference in the similar age dyads is significant only at the $\mathrm{p}<.10$ level.
} 

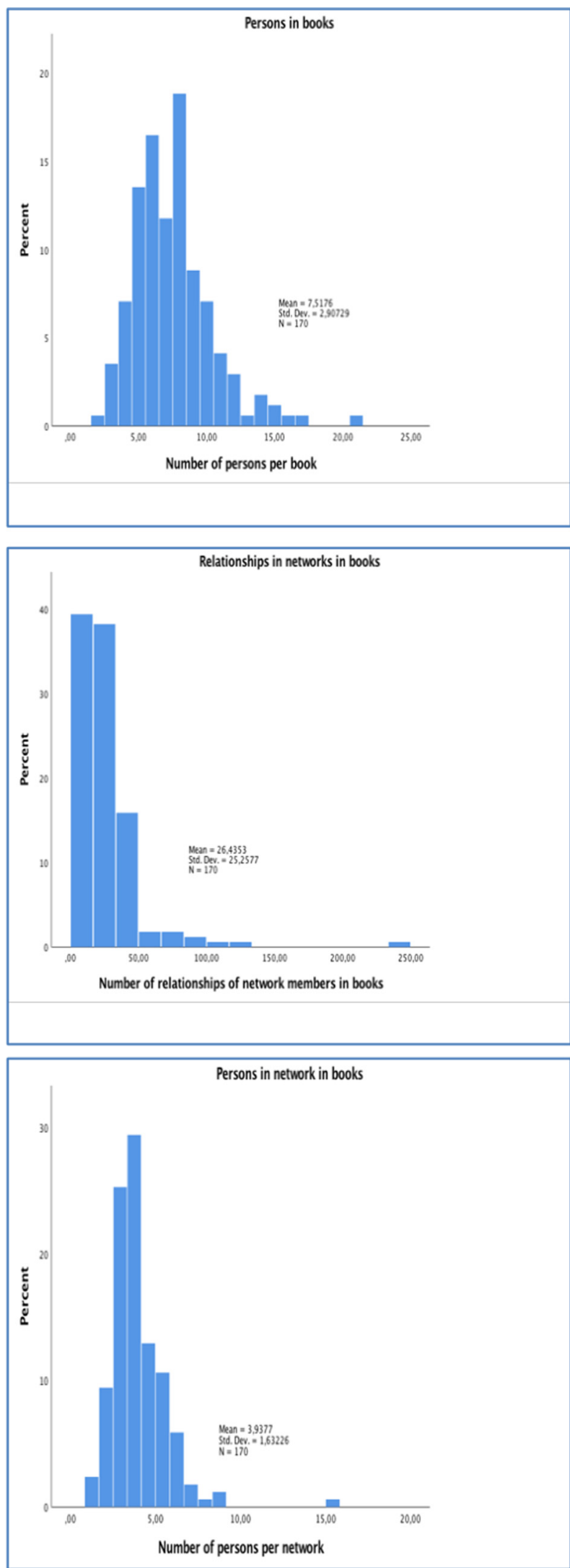

Fig. 1. Number of persons in books, number of network members and number of relationships (LIBRIS data). 


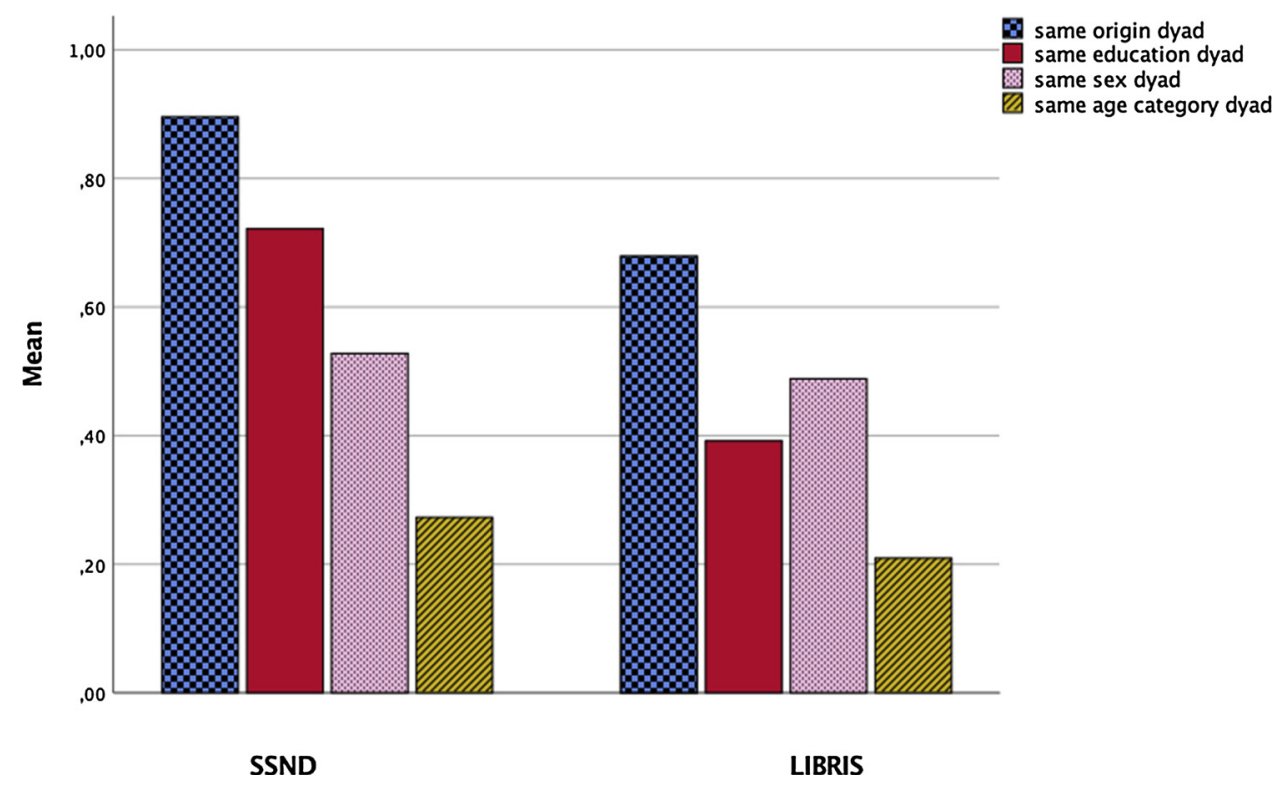

Fig. 2. Similarity of dyads in networks of people and books (SSND $n=967$ and LIBRIS $n=170$ ).

Table 5a

Predicting origin-similarity in dyads (summary table).

\begin{tabular}{llll}
\hline SSND & OR & z value & P value \\
\hline ego origin (Dutch) & 24.212 & 9.850 & 0.000 \\
same education & 1.520 & 2.230 & 0.026 \\
same age & 1.704 & 2.500 & 0.012 \\
negative relation & 0.631 & -1.85 & 0.065 \\
sum alters NL & 3.162 & 8.650 & 0.000 \\
network size & 0.396 & -7.540 & 0.000 \\
ICC & 0.390 & & $\mathrm{p}$ value \\
LL & -705.70 & & 0.002 \\
\hline LIBRIS & OR & $\mathrm{z}$ value \\
\hline ego origin NL & 2.44 & 3.05 & 0.012 \\
ego education & 0.366 & -2.51 & 0.000 \\
same age & 5.762 & 4.38 & 0.000 \\
negative relation & 0.037 & -3.88 & 0.003 \\
partner/lover & 0.209 & -2.96 & 0.008 \\
origin author (Dutch) & 0.002 & -2.64 & \\
ICC & 0.793 & & \\
LL & -266.871 & & \\
\hline
\end{tabular}

Note: controlled for all ego characteristics, author characteristics (in the LIBRIS data), role relationships and opportunity structure.

educational similarity in a dyad.

The analysis of age similarity (Table 5d) shows for the SSND that people in higher age groups are less likely to have age similar alters in their networks than younger people. In the LIBRIS data, this holds for only people in the middle age group. Furthermore, age similarity is associated with similarity in origin in both data and with similarity in education in the literary data. Last but not least partners are likely to be similar in age in the LIBRIS data, while in the SSND, friendship relations predict age similarity.

Before moving to the conclusion, we report a last inquiry, done in order to tackle the role of authors in the social structures depicted in books a bit more. ${ }^{11}$ All in all, the multivariate analyses have shown that author characteristics do not matter on average. This does however not take away that authors with a given characteristic - e.g. born outside of the Netherlands - might see the world

\footnotetext{
${ }^{11}$ We thank one of the anonymous reviewers, who suggested this type of analysis.
} 
Table 5b

Predicting sex-similarity in dyads (summary table).

\begin{tabular}{|c|c|c|c|}
\hline SSND & OR & $\mathrm{z}$ value & $\mathrm{p}$ value \\
\hline male (ego) & 2.597 & 10.480 & 0.000 \\
\hline multiplexity & 0.473 & -3.336 & 0.001 \\
\hline partner & 0.037 & -5.620 & 0.000 \\
\hline colleague & 2.470 & 8.600 & 0.000 \\
\hline friend & 3.010 & 8.010 & 0.000 \\
\hline negative relation & $\mathrm{ns}$ & $\mathrm{ns}$ & ns \\
\hline similarity in education & $\mathrm{ns}$ & $\mathrm{ns}$ & ns \\
\hline ICC & 0.059 & & \\
\hline LL & -1979.80 & & \\
\hline LIBRIS & $\mathrm{OR}$ & $\mathrm{z}$ value & $\mathrm{p}$ value \\
\hline male (ego) & 3.36 & 3.56 & 0.000 \\
\hline multiplexity & 0.46 & -3.34 & 0.001 \\
\hline partner & 0.03 & -7.49 & 0.000 \\
\hline colleague & 2.76 & 3.17 & 0.002 \\
\hline friend & 2.06 & 2.08 & 0.038 \\
\hline negative relation & 3.89 & 2.54 & 0.011 \\
\hline similarity in education & 2.55 & 3.55 & 0.000 \\
\hline $\mathrm{N}$ men in book & 0.88 & -2.37 & 0.018 \\
\hline ICC & 0.22 & & \\
\hline LL & -401.852 & & \\
\hline
\end{tabular}

Note: controlled for all ego characteristics, author characteristics (in the LIBRIS data), role relationships and opportunity structure.

Table 5c

Predicting educational similarity in dyads (summary table).

\begin{tabular}{|c|c|c|c|c|}
\hline SSND & OR & & $\mathrm{z}$ value & $\mathrm{p}$ value \\
\hline high education (ego) & 0.301 & & -9.04 & 0.000 \\
\hline ego from the Netherlands & 0.494 & & -2.76 & 0.006 \\
\hline negative relation & 1.30 & & 1.76 & 0.078 \\
\hline friend & 1.62 & & 3.16 & 0.002 \\
\hline partner & 1.50 & & 1.88 & 0.040 \\
\hline colleague & 2.48 & & 7.35 & 0.000 \\
\hline same origin & 1.50 & & 2.18 & 0.029 \\
\hline ICC & 0.236 & & & \\
\hline LL & -1890.46 & & & \\
\hline LIBRIS & & OR & $\mathrm{z}$ value & $\mathrm{p}$ value \\
\hline high education (ego) & & 6.947 & 4.690 & 0.000 \\
\hline negative relation & & 0.184 & -2.80 & 0.005 \\
\hline colleague & & 0.327 & -2.82 & 0.005 \\
\hline same sex & & 3.293 & 4.22 & 0.000 \\
\hline same age & & 2.741 & 3.57 & 0.000 \\
\hline $\mathrm{N}$ persons in book & & 1.189 & 2.01 & 0.045 \\
\hline Author background in Humanities (ref: social sciences) & & 7.882 & 6.440 & .012 \\
\hline ICC & & 0.552 & & \\
\hline LL & & -337.364 & & \\
\hline
\end{tabular}

Note: controlled for all ego characteristics, author characteristics (in the LIBRIS data), role relationships and opportunity structure.

similar as people with the same characteristic and hence built similar networks - in fiction as in real life. Therefore, we selected books written by authors with a given characteristic and compared the networks in these books to the networks of people with the same characteristic. We started with selecting higher educated from the sample of respondents in the SSND, since the authors are in general relatively high educated. Next, we compared books written by authors born inside and outside the Netherlands, respectively, to similar respondents and, finally we compared books written by older and younger authors respectively with corresponding respondents. For these corresponding books and persons, we compared the different dimensions of similarity. We deliberately did not 
Table 5d

Predicting age similarity in dyads (summary table).

\begin{tabular}{llll}
\hline SSND & OR & z value & p value \\
\hline age ego $<45$ (ref = below 25) & 0.369 & -2.07 & 0.039 \\
age ego $<55$ & 0.356 & -2.18 & 0.029 \\
age ego $<65$ & 0.214 & -3.24 & 0.001 \\
age ego $<65+$ & 0.234 & -3.02 & 0.002 \\
same origin & 1.531 & 2.230 & 0.026 \\
multiplexity & 0.614 & -2.060 & 0.039 \\
friend & 3.405 & 9.440 & 0.000 \\
ICC & 0.068 & & P value \\
LL & -175.04 & & 0.047 \\
\hline LIBRIS & OR & z value & \\
\hline age ego 35-45 (ref $<25-34)$ & 0.422 & -1.98 & 0.000 \\
$\quad$ (other age categories: ns) & & & 0.000 \\
same origin & 4.368 & 4.30 & 0.000 \\
same educational level & 2.968 & 3.89 & 0.000 \\
friend & 5.100 & 4.04 & 0.039 \\
partner/lover & 8.450 & 5.71 & 2.06 \\
multiplexity & 1.64 & & \\
ICC & 0.444 & & \\
LL & -372.889 & & \\
\hline
\end{tabular}

Note: controlled for all ego characteristics, author characteristics (in the LIBRIS data), role relationships and opportunity structure.

compare men and women, since there was no significant difference in the sex similar dyads between networks in books and networks in the actual world. Table 6 shows the results.

When comparing only higher educated respondents' networks to the networks in books, the table shows that the absolute t-values

Table 6

Similarity in dyads when matching books and people by author's characteristics (mean, sd).

\begin{tabular}{|c|c|c|c|c|c|c|}
\hline \multirow[b]{2}{*}{ Similarity dimension } & \multicolumn{3}{|c|}{ All books and respondents } & \multicolumn{3}{|c|}{ Only higher educated respondents } \\
\hline & LIBRIS & SSND & absolute t-value & LIBRIS & SSND & absolute t-value \\
\hline sex & $0.488(.500)$ & $0.527(.499)$ & 0.938 & $0.488(.500)$ & $0.561(.486)$ & 1.614 \\
\hline country of birth & $0.678(.460)$ & $0.895(.306)$ & $7.800^{* * *}$ & $0.678(.460)$ & $0.910(.535)$ & $3.620 * *$ \\
\hline education & $0.391(.480)$ & $0.721(.448)$ & $8.748^{* *}$ & $0.391(.480)$ & $0.535(.499)$ & $4.017^{* * * *}$ \\
\hline age & $0.209(.400)$ & $0.272(.445)$ & 1.796 & $0.209(.400)$ & $0.316(.465)$ & $2.553^{* *}$ \\
\hline $\mathrm{N}$ & 170 & 950 & & 170 & 330 & \\
\hline
\end{tabular}

\begin{tabular}{|c|c|c|c|c|c|c|}
\hline \multirow[b]{3}{*}{ Similarity dimension } & \multicolumn{6}{|c|}{ Selection of authors (books) and respondents: } \\
\hline & \multicolumn{3}{|c|}{$\begin{array}{l}\text { born in the Netherlands } \\
\text { (and highly educated) }\end{array}$} & \multicolumn{3}{|c|}{$\begin{array}{l}\text { not born in the Netherlands } \\
\text { (and highly educated) }\end{array}$} \\
\hline & LIBRIS & SSND & absolute t-value & LIBRIS & SSND & absolute t- value \\
\hline sex & $0.498(.500)$ & $0.569(.495)$ & 1.394 & $0.447(.498)$ & $0.381(.497)$ & 0.542 \\
\hline country of birth & $0.628(.483)$ & $0.928(.258)$ & $8.339 * * *$ & $0.877(.328)$ & $0.523(.511)$ & $3.149 * *$ \\
\hline education & $0.404(.491)$ & $0.542(.498)$ & $2.715^{* *}$ & $0.343(.476)$ & $0.381(.497)$ & 0.316 \\
\hline age & $0.193(.395)$ & $0.322(.468)$ & $2.829 * *$ & $0.273(.446)$ & $0.190(.402)$ & 0.813 \\
\hline \multirow[t]{2}{*}{$\mathrm{N}$} & 144 & 280 & & 25 & 50 & \\
\hline & \multicolumn{3}{|c|}{$\begin{array}{l}\text { Older than } 55 \text { years of age } \\
\text { (and higher educated) }\end{array}$} & \multicolumn{3}{|c|}{$\begin{array}{l}\text { Younger than } 45 \text { years of age } \\
\text { (and higher educated) }\end{array}$} \\
\hline Similarity dimension & LIBRIS & SSND & absolute t-value & LIBRIS & SSND & absolute t- value \\
\hline $\operatorname{sex}$ & $0.491(.500)$ & $0.550(.498)$ & 0.746 & $0.477(.500)$ & $0.577(.495)$ & 1.221 \\
\hline country of birth & $0.697(.460)$ & $0.918(.274)$ & $3.750 * *$ & $0.616(.486)$ & $0.902(.297)$ & $4.751 * * *$ \\
\hline education & $0.427(.495)$ & $0.512(.501)$ & 1.076 & $0.418(.494)$ & $0.542(.499)$ & 1.511 \\
\hline age & $0.195(.224)$ & $0.277(.440)$ & 0.566 & $0.230(.421)$ & $0.360(.481)$ & 1.700 \\
\hline $\mathrm{N}$ & 74 & 86 & & 53 & 120 & \\
\hline
\end{tabular}

Note: $* \mathrm{p}<.05, * * \mathrm{p}<.005, * * \mathrm{p}<.001$. 
for the differences between the samples become smaller, with the exception of age similar dyads (increase from 1.796 to 2.553 ). This indicates that similarity of age-dyads for the higher educated is higher in real life than in books. When making the comparison with regard to origin, the table reveals that the t-value for the differences in origin similarity increased from 7.800 to 8.339. Dutch born authors depict networks clearly less homogeneous with respect to origin than they are in the actual world. Furthermore, the difference in the mean dyad similarity of education becomes smaller, though, but that of age becomes larger. Hence real-world networks of people born in the Netherlands are in particular more homogenous in terms of origin and age than the networks depicted by Dutch authors, while the segregating role of education is maintained. Interestingly, when comparing books by authors with a foreign origin with respondents, who also have a non-Dutch background, all similarity dimensions do not differ, except the dimension of origin: authors with a non-Dutch background depict networks that are more segregated by ethnicity than the networks of their real-world counterparts actually are. On the contrary, networks of foreign-born people are more diverse in terms of origin than the networks of their Dutch counterparts (average similarity is 0.523 compared to 928.) Finally, when making the comparison in terms of age networks again become more similar, while the difference in terms of origin remains most pronounced.

\section{Conclusion and discussion}

Our comparison of fictional networks in Dutch literature with actual networks of people living in the Netherlands revealed a number of interesting findings. First, the population of characters in literary fiction differs from the population in the Netherlands. Lower educated, and elderly people are underrepresented in books, while foreign-born people are overrepresented. Second, when looking at the different role relations in personal networks, we see that in fictional networks, marriage partners or lovers are more often featured than in actual social networks, while the percentages of family and friends are relatively similar. Furthermore, neighbors have a vital role relationship in the actual networks, but they do not form relevant relational categories in the fictional ones.

Third, when looking at the similarity in dyadic relationships, we found that in particular the dyads among network members in terms of education and origin are considerably less similar in books than in actual networks. Higher aged characters in books have more age similar dyads than people in the real world and the same holds for education: high educated characters' networks are more homogeneous in terms of education than networks of high educated persons in the actual world. Closure at the top seems even more pronounced in novels than in the real world.

Finally, the multilevel models largely confirmed the description of the data and the number of interesting parallels as well as disparities between novels and actual social networks. In the novels but not so much in the real-world, sex similar characters are also likely to have a similar education. In the novels, more so than in the real world, high educated characters are very likely to have high educated network members - although educational segregation is on average higher in the real world. In addition, educational similarity in novels is predicted by other similarity dimensions, such as sex and age, a finding which also points towards social closure. When analyzing age similarity, in both data, younger age groups have less similar dyads than older age groups, but friends usually are in the same age group. In the fictional networks but not in the actual ones, lovers/partners have also a higher chance of a different origin. This latter finding probably adds 'tension' to literary stories.

In a last step we selected authors with certain characteristics and compared networks in their books with networks of people with the same characteristics. While networks of people and in books by and large became more similar because of this selection, we found that authors with a foreign origin depict more segregation - with respect to origin - in the networks of their characters than actually exists in corresponding real-world networks. Conversely, authors who are born in the Netherlands seem to 'underestimate' the actual degree of segregation with respect to origin.

Another important finding is that everyday life seems often not interesting enough to write about. While in networks of actual persons neighbors are vital relationships, they are as good as absent in the high-brow novels. On the other hand, relationships to lovers and partners are much more prominent in the novels than in the actual world. Interestingly, the role of friends and family is very much comparable, so, in this sense literature mirrors our social worlds. These findings touch upon the question of 'what makes a popular piece of art'? This probably differs among cultures, generations, periods, and institutional settings. In contemporary Dutch society the focus in many art products is on individual luck, which might explain why partners or lovers are that important. Interestingly, in many science fiction writings, romantic love plays a far less prominent role, but friendship, community and (social) sustainability are the crucial topics (see, e.g. More, 1965, Casper, 2016, or Thompson, 1984).

In conclusion, it seems that in some ways, literature mirrors the actual social world, but in many ways, it is clearly another world. In particular the integration of people with another ethnic origin is better established in literary fiction than in the actual world. In terms of education, there is more closure in the higher social strata and with regard to age, in particular the higher aged characters in books have also an age homogeneous network. In addition, authors sometimes seem to play with segregation boundaries: romantic lovers in the books but not in the real world have an increased likelihood of differences in origin.

Our analysis contributes to the discussion about the role of literature in society in several ways. We show that there are considerable similarities, but the fictional mirror has also blind spots. In the future, it would be worthwhile to inquire more systematically into the process of writing and what social factors account for the networks in books. For example, Childress (2017) showed for one specific book the social structures that influenced its creation, production, and reception. Extending this research and compare social situations of different authors in different social settings would teach us more about how literary fiction corresponds with society.

Our analysis has some important limitations, though. We argued that there are two principles that account for similarity in relationships, structural meeting opportunities and preferences. In our analyses we accounted explicitly for the former, but we found 
not much evidence that opportunity structure matters for relationships among characters in books. However, our measurements were relatively crude, we just controlled for the number of people with a certain characteristic in the books or in the network, as a proxy for the opportunity structure of interaction. With this type of operationalization, also in the real-life networks we did not find much evidence for the impact of opportunity structures. In studies about actual network formation, opportunities have been shown to matter (Mollenhorst et al., 2008). Furthermore, the number of missing values on some socio demographic characteristics is high. In addition, one can argue that the sample - books submitted to the LIBRIS prize - is selective as it consists of relatively highbrow works of literature. It would be important to compare our findings with findings from a sample of lowbrow literature (e.g. bouquet series) or genre-fiction (e.g. fantasy, science-fiction). It might be that in particular the books submitted to the LIBRIS prize provide something 'extraordinary' that points towards alternative worlds, while lowbrow fiction more often pictures rather traditional social structures. Hopefully, future research will shed light on the question whether books from different literary genres consist of different networks of relationships among the characters.

Another limitation of our research is that we did not account for narrative structures and literary style. It might be that the relations between dissimilar characters are unequally portrayed in terms of power or just weaker than those between similar ones. Stereotypical descriptions can produce imbalances between characters in more subtle ways than we have considered in this article. E.g., research on the representation of gender and race in visual media such as Hollywood films shows that stereotypes of women and racial/ethnic minorities are persistent (Erigha, 2015; Signorielli, 1989). Again, we hope that future studies will align our findings with this strand of research on cultural stereotypes.

To conclude, issues around social divides and segregation in society are also issues in modern literature in the Netherlands. On average, it seems that integration of people from different cultural origins is tackled in Dutch literary fiction. This brings to mind the controversial claim by Vaessens (2011), who stated that a turn towards political and social reality is noticeable in contemporary Dutch literature, as some recent novels tend to be more and more engaged with societal issues. Our findings on ethnic composition of literary networks do indeed suggest that contemporary fiction breaks open traditional social structures, at least in some respects.

All in all, the comparison between networks in books with the actual world seems to be a promising step towards the understanding of the relation between literature and society as well as towards the application of quantitative network analysis and largescale data analysis in the field of humanities.

\section{Acknowledgements}

We thank the members of the Department of Sociology at the University of Amsterdam as well as the members of the Department of Modern Language and Culture at the University of Nijmegen (The Netherlands), who commented on drafts of this paper. In addition, we are very thankful to the anonymous reviewers and to the editor, whose helpful comments considerably improved this paper.

\section{References}

Abrams, M. H. (1953). The mirror and the lamp: Romantic theory and the critical tradition. Oxford: Oxford University Press.

Allan, G. (1977). Class variation in friendship patterns. The British Journal of Sociology, 28(3), 389-393.

Anjana, B. K., \& Bhambhra, R. L. (2016). Is Literature the mirror of society? International Journal of English Language, Literature and Humanities, 4, 3.

Anjaria, U. (2017). Twenty-first-century realism. Oxford research encyclopedias online, visited March 2019.

Aristoteles (2013 [335 BC]). Poetics. Trans. A. Kenny. Oxford: Oxford University Press.

Auerbach, E. (2003 [1946]) Mimesis: The representation of reality in Western Literature. Fiftieth anniversary edition. Princeton: Princeton University Press.

Blau, P. (1977). Inequality and heterogeneity. New York: Free Press.

Bourdieu, P. (1981). Le capital sociale. Notes provisoires. Actes de la Recherche en Sciences Sociales, 31, 2-3.

Booth, A., \& Hess, E. (1974). Cross-sex friendships. Journal of Marriage and the Family, 1, 38-47.

Briggs, X. (2001). Ties that bind, bridge, and constrain: Social capital and segregation in the American metropolis. International seminar on segregation and the City. Cambridge: Lincoln Institute of Land Policy jul. (www.lincolninst.edu/).

Britton, M. L. (2011). Close together but worlds apart? Residential integration and interethnic friendship in Houston. City \& Community, 10(2), 182-204.

Casper, C. (2016). The mercy journals. Vancouver: Arsenaal Pulp Press.

Chan, T. W., \& Goldthorpe, J. H. (2004). Is there a status order in contemporary British society? Evidence from the occupational structure of friendship. European Sociological Review, 5, 383-401.

Childress, C. (2017). Under the cover: The creation, production, and reception of a novel. Princeton: Princeton University Press.

Curry, T. J., \& Emerson, R. M. (1970). Balance theory: A theory of interpersonal attraction? Sociometry, 33(2), 216-238.

Dickstein, M. (2007). A mirror in the roadway: Literature and the Real World. Princeton: Princeton University Press.

Erigha, M. (2015). Race, gender, hollywood: Representation in cultural production and digital media's potential for change. Sociology Compass, 9(1), 78-89.

Feld, S. L. (1981). The focused organization of social ties. American Journal of Sociology, 86, 1015-1035.

Fischer, C. S. (1982). To dwell among friends. Chicago: University of Chicago Press.

Fischer, C. S., Jackson, R. M., Stueve, C. A., Gerson, K., Mcallister Jones, L., \& Baldassare, M. (1977). Networks and places. Relations in the urban setting. New York: Free Press.

Flap, H., \& Volker, B. (Eds.). (2004). Creation and returns of social capital. A new research program. London: Routledge.

Heider, F. (1946). Attitudes and cognitive organization. Journal of Psychology, 21, 107-112.

Hoggart, R. (1966). Literature and society. The American Scholar, 35(2), 277-289.

Homans, G. C. (1950). The human group. New York: Harcout.

Homans, G. C. (1984). Coming to my senses. The autobiography of a sociologist. New Brunswick, N.J: Transaction Books.

Kalmijn, M. (1998). Intermarriage and homogamy: Causes, patterns, trends. Annual Review of Sociology, 24(1), 395-421.

Kalmijn, M. (2002). Sex segregation of friendship networks. Individual and structural determinants of having cross-sex friends. European Sociological Review, 18(1), 101-117.

Markovsky, B., \& Lawler, E. J. (1994). A new theory of group solidarity [electronic version]. Retrieved May, 1, 2019, from Cornell University, ILR School site:http:// digitalcommons.ilr.cornell.edu/articles/1157. 
Marsden, P. (1986). Core discussion networks of Americans. American Sociological Review, 52, 122-131.

Marsden, P. (1990). Network diversity, substructures and opportunities for contacts. In C. Calhoun, M. W. Meyer, \& W. R. Scott (Eds.). Structures of power and constraints (pp. 397-410). Cambridge: Cambridge University Press.

McPherson, M., Smith-Lovin, L., \& Cook, J. M. (2001). Birds of a feather: Homophily in social networks. Annual Review of Sociology, $27(1)$, 415-444.

Mollenhorst, G., Volker, B., \& Flap, H. (2008). Social contexts and core discussion networks: Using a choice constraint approach to study similarity in intimate relationships. Social Forces, 86, 937-965.

More, T. (1965 [1516]). Utopia. Translated by Paul Turner. Harmondworth: Penguin.

Newcomb, T. (1961). The acquaintance process. New York: Holt, Rinehart and Winston.

Pettigrew, T. F. (1998). Intergroup contact theory. Annual review of psychology, 49(1), 65-85.

Plato. (1968 [ca 360 BC]). Laws. Plato in Twelve Volumes, Vol. 11. Bury translator. Cambridge: Harvard University Press.

Rydgren, J., Sofi, D., \& Hällsten, M. (2013). Interethnic friendship, trust, and tolerance: Findings from two north Iraqi cities. American Journal of Sociology, 118(6), $1650-1694$.

Smith, S. (2017). Befriending the same differently: Ethnic, socioeconomic status, and gender differences in same-ethnic friendship. Journal of Ethnic and Migration Studies, $1-23$.

Sontag, S. (1966). Against interpretation. New York: Farrar, Straus and Giroux.

Stowe, H. B. (1981 [1852]). Uncle Tom's Cabin, or, Life Among the Lowly. New York: Penguin.

Thompson, J. (1984). Conscience Place. New York: Doubleday \& Company, Inc.

Vaessens, T. (2011). Dutch novelists beyond 'postmodern' relativism. Journal of Dutch Literature, 2(1).

Van der Deijl, L. A., Prinse, M., Pieterse, S., \& Smeets, R. (2016). Mapping the demographic landscape of recent Dutch prose: A quantitative approach to literary representation. Journal of Dutch Literature, 7(1), 20-42.

Verbrugge, L. M. (1977). The structure of adult friendship choices. Social Forces, 56(2), 576-597.

Volker, B., \& Mollenhorst, G. (2014). The survey of the social networks of the Dutch. Utrecht 2014.

Signorielli, N. (1989). Television and conceptions about sex roles: Maintaining conventionality and the status quo. Sex Roles, 21(5-6), 341-360.

Statistics Netherlands (CBS) https://opendata.cbs.nl/statline/\#/CBS/nl/ visited January 2018.

Snijders, T., \& Bosker, R. (1999). Multilevel analysis: An introduction to basic and applied multilevel analysis. London: Sage.

Wasserman, S., \& Faust, K. (1994). Social network analysis: Methods and applications, Vol. 8. Cambridge: Cambridge University Press.

Beate Volker is full professor of Sociology and chair of the research group 'Institutions, Inequality and Life Courses'. Volker conducts research in social networks in different settings such as neighbourhoods and labour organisations. She has worked as a fellow at the Royal Netherlands Academy of Arts and Sciences (KNAW) and has been a full professor since 2007. Up until 2012, her chair was financed by the Van der Gaag Fund/KNAW with the aim of studying the sociological components of prosocial behaviour. Volker has been the recipient of various research grants, she is a member of the European Academy of Sociology, the Royal Holland Society of Sciences and Humanities, and of the editorial board of the academic journal Social Networks.

Roel Smeets is a lecturer in literary studies and an expert in computational and quatitative methods for literary studies. He works on ideological criticism of literature and on relational patterns between characters in the literature and aims at integrating social research methods with humanities. Previously he was employed as secretary for the research programme 'Cultural Infrastructure And Reception Across Borders'. and LIBRIS n = 170). 